\title{
An experimental investigation of heat transfer enhancement in minichannel: Combination of nanofluid and micro fin structure techniques
}

\author{
Zhang, Ji; Diao, Yanhua; Zhao, Yaohua; Zhang, Yanni
}

\section{Published in:}

Experimental Thermal and Fluid Science

Link to article, DOI:

10.1016/j.expthermflusci.2016.10.001

Publication date:

2017

Document Version

Peer reviewed version

Link back to DTU Orbit

Citation (APA):

Zhang, J., Diao, Y., Zhao, Y., \& Zhang, Y. (2017). An experimental investigation of heat transfer enhancement in minichannel: Combination of nanofluid and micro fin structure techniques. Experimental Thermal and Fluid Science, 81, 21-32. https://doi.org/10.1016/j.expthermflusci.2016.10.001

\section{General rights}

Copyright and moral rights for the publications made accessible in the public portal are retained by the authors and/or other copyright owners and it is a condition of accessing publications that users recognise and abide by the legal requirements associated with these rights.

- Users may download and print one copy of any publication from the public portal for the purpose of private study or research.

- You may not further distribute the material or use it for any profit-making activity or commercial gain

- You may freely distribute the URL identifying the publication in the public portal 


\title{
An experimental investigation of heat transfer enhancement
} in minichannel: combination of nanofluid and micro fin

\section{structure techniques}

\author{
Ji Zhang ${ }^{\text {a,b,c }}$, Yanhua Diao ${ }^{\text {b,* }}$, Yaohua Zhao ${ }^{b}$, Yanni Zhang ${ }^{b}$ \\ ${ }^{\text {a }}$ Key Laboratory of Hydroelectric Machinery Design \& Maintenance, China Three \\ Gorges University, Yichang 443002, China \\ ${ }^{\mathrm{b}}$ Department of Building Environment and Facility Engineering, Beijing University of \\ Technology, No.100 Pingleyuan, Chaoyang District, Beijing 100124, China \\ c Department of Mechanical Engineering, Technical University of Denmark, Nils \\ Koppels Allé, Building 403, 2800 Kongens Lyngby, Denmark
}

\section{Abstract}

This work experimentally studied the single-phase heat transfer and pressure drop characteristics by using two heat transfer enhancement techniques (micro fin structure and nanofluids) in multiport minichannel flat tube (MMFT). MMFT consisted of numerous parallel rectangular minichannels and is widely used in industry as the heat transfer unit of a heat exchanger. Firstly, the enhanced heat transfer performances by individually using one enhancement technique were investigated by testing Nusselt number, friction factor and performance evaluation criterion (PEC). In this section, five MMFTs with different micro fin numbers $(\mathrm{N}=0,1,2,3$ and 4) and nanofluids with three volume concentrations $(\varphi=0.005 \%, 0.01 \%$ and $0.1 \%)$ were used as test sections and working fluids respectively. Secondly, the experiments using two combined

\footnotetext{
* Corresponding author. Tel.: +86 010 67391608-802; fax: +86 010 67391608-802

E-mail address: diaoyanhua@ bjut.edu.cn (Y.H. Diao)
} 
1 enhancement technique were performed. By using conjunctively two enhancement

2 techniques, Nusselt number increases by up to $158 \%$ at about $\operatorname{Re}=3600$ and the maximum PEC value can reach 2.0 at $\mathrm{Re}=5150$. Finally, an optimal heat transfer

4 scheme was proposed based on test data.

5 Keywords: multiport minichannel flat tube, heat transfer enhancement, micro fin

6 structure, nanofluid, PEC

\begin{tabular}{|c|c|c|c|}
\hline \multicolumn{4}{|c|}{ Nomenclature } \\
\hline A & total wetted area, $\mathrm{m}^{2}$ & \\
\hline C & wetted perimeter, $\mathrm{m}$ & \multicolumn{2}{|c|}{ Greek Symbols } \\
\hline$c_{p}$ & specific heat capacity, J/kg K & & \\
\hline d & diameter, $\mathrm{m}$ & $\alpha$ & aspect ratio, b/a $(0<\alpha<1)$ \\
\hline $\mathrm{D}_{\mathrm{h}}$ & hydraulic diameter, $\mathrm{m}$ & $\varphi$ & volume concentration \\
\hline$f$ & friction factor & $\mu$ & dynamic viscosity, Pa•s \\
\hline$\dot{\mathrm{m}}$ & mass flow rate, $\mathrm{kg} / \mathrm{s}$ & $\rho$ & mass density, $\mathrm{kg} / \mathrm{m}^{3}$ \\
\hline $\mathrm{H}$ & Height, $\mathrm{m}$ & & \\
\hline $\mathrm{h}$ & heat transfer coefficient, $\mathrm{W} / \mathrm{m}^{2} \mathrm{~K}$ & & \\
\hline $\mathrm{k}$ & thermal conductivity, $\mathrm{W} / \mathrm{m} \mathrm{K}$ & \multicolumn{2}{|c|}{ Subscripts } \\
\hline $\mathrm{L}$ & length, $\mathrm{m}$ & $b f$ & base fluid \\
\hline MMFT & multiport minichannel flat tube & $f$ & fluid \\
\hline $\mathrm{Nu}$ & Nusselt number & $n f$ & nanofluid \\
\hline $\mathrm{Pe}$ & perimeter, $\mathrm{m}$ & $c$ & channel \\
\hline PEC & performance evaluation criterion & fin & fin \\
\hline $\operatorname{Pr}$ & Prandtl number & in & inlet \\
\hline$\Delta \mathrm{P}$ & total pressure differential, $\mathrm{Pa}$ & out & outlet \\
\hline$\Delta \mathrm{P}_{\text {fri }}$ & frictional pressure loss, $\mathrm{Pa}$ & $w$ & wall \\
\hline$\Delta \mathrm{P}_{\mathrm{m}}$ & singular pressure loss, $\mathrm{Pa}$ & & \\
\hline q & heat flux, $\mathrm{W} / \mathrm{m}^{2}$ & & \\
\hline Q & heat transfer rate gained by fluid, $\mathrm{W}$ & & \\
\hline $\operatorname{Re}$ & Reynolds number & & \\
\hline $\mathrm{T}$ & temperature, ${ }^{\circ} \mathrm{C}$ & & \\
\hline $\mathrm{x}$ & axial distance, $\mathrm{m}$ & & \\
\hline W & Weight, $\mathrm{m}$ & & \\
\hline
\end{tabular}




\section{Introduction}

With the pioneering work of Tuckerman and Pease [1] in early 1981, concept of microchannel heat sinks was first demonstrated and potential heat flux removal rate of the order $1000 \mathrm{~W} / \mathrm{cm}^{2}$ for single-phase forced convective cooling in microchannels was predicted. After that, micro-scale heat transfer in micro/minichannel has become increasingly popular and been applied in various fields due to their large surface area to volume ratios and high heat transfer coefficients. Moreover, it is of critical significance to develop the heat transfer enhancement techniques in micro/minichannel, confronted fast growing power consumption, energy and materials savings, high heat flux removal and device miniaturization. In a review of heat transfer in microchannels presented by Kandlikar et al. [2], it states that enhancing heat transfer in microchannels is of critical importance in successful development of microscale thermal devices. The heat transfer coefficient needs to be further increased, while dramatic reductions in pressure drop are warranted.

Wu and Sundén [3] performed a state-of-the-art overview of the most recent singlephase flow enhancement techniques, where microfins and additives were summarized as two key approaches to improve single-phase thermal performance in micro/minichannels. It was concluded that micro/minichannels within interrupted microfins are very promising for high heat-flux dissipation. Engineered fluids with additives, very popular in research during the last ten years, maybe an efficient way to significantly improve the thermal performance without large pressure drop penalty. For microfin structure, many literatures have proved that this technique can significantly 
1 enhance heat transfer performance [4-7]. Lee et al. [8] performed an experimental

2 investigation into enhancing heat transfer by employing sectional oblique fins in

3 microchannel heat sink. The results found that heat transfer performance of the

4 enhanced microchannel is greatly augmented and when the Reynolds number is

5 increased beyond 600, heat transfer enhancement reaches 2.2. Meanwhile, nanofluid as

6 the most common product of particle additives also shows great ability to improve the

7 thermal performance in micro/minichannel [9-11]. Ho et al. [12] experimentally

8 investigated the forced convective cooling performance of a copper microchannel heat

9 sink with $\mathrm{Al}_{2} \mathrm{O}_{3}$-water nanofluid as the coolant. For the largest flow rate tested for the

nanofluid of 1 vol.\%, the average heat transfer coefficient increased by about $70 \%$ compared with that with water.

Based on above research results, in order to achieve the better heat transfer performance, the combined effects of micro fin structure and nanofluids on the heat transfer enhancement in the microchannel are worth to be expected. However, the enhanced heat transfers using micro fins and nanofluids often accompany complicated mechanism, especially for nanofluids. As concluded in Ref. [13], low weight percentages of nanoparticles seem to provide the best performance. The mechanisms for enhanced lubrication performance are manifold and depend on the material structure of the nanoparticles. Moreover, in the literatures about single-phase flow heat transfer of nanofluid in smooth micro/minichannel, some novel phenomena have been found including the delay of laminar-turbulent transition [14] and discrete precipitation of agglomerated nanoparticles in the channel [15]. Therefore, applicability that using 
nanofluids in micro/minichannel with micro fin to enhance heat transfer should be further studied. Furthermore, from the literature survey, it can be found that the experimental investigations combining micro fin and nanofluids are much less compared with those just using one enhancement technique. Therefore, more investigations regarding the research of combined these two enhancement techniques should be performed, which have significance to further study the comprehensive strengthening effect and design the optimal enhanced heat exchange scheme.

Few research regarding flow and heat transfer characteristics of nanofluid in micro/minichannel with micro fin structure have been presented in the open literatures. Aliabadi et al. [16] performed an experimental assessment of the copper-water nanofluid flow through seven plate-fin channels. It was found that the best thermalhydraulic performance is obtained by the vortex in comparison with the plain one generator. Meanwhile, the use of nanofluid in this channel had more benefit at the lower flow rates and high nanoparticles weight fractions. Roshani et al. [17] investigated experimentally the hydrodynamic and thermal performance of a miniature plate pinfinned heat sink by utilizing two widely used nanofluids, $\mathrm{Al}_{2} \mathrm{O}_{3}$-water and $\mathrm{TiO}_{2}$-water. The results found that although $15 \%$ and $30 \%$ increase in the pumping power for the volume concentration of $2 \% \mathrm{Al}_{2} \mathrm{O}_{3}-$ water and $\mathrm{TiO}_{2}$-water nanofluids, respectively, the average heat transfer coefficients increased by $16 \%$ and $14 \%$ and the thermal resistance decreased by $17 \%$ and $14 \%$ for each nanofluid. Eiamsa-ard and Wongcharee [18] conducted an experimental research to study the effect of combined heat transfer enhancement techniques (dual twisted-tapes, a micro-fin tube as well as nanofluids) on 
heat transfer, friction factor and thermal performance factor. The test results indicated that the beneficial effect for the energy saving by the uses of the combined techniques, especially at low Reynolds number. Duangthongsuk and Wongwises [19] reported an experimental investigation into the thermal performance and pressure drop characteristics of nanofluid-cooled heat sinks with miniature circular-fin and square-fin structures. The experimental results indicated that the heat transfer coefficient increased with increasing Reynolds numbers and particle concentrations. The miniature circularfin gave greater heat transfer performance than that of the square-fin by about 6-9\%. From the current research which show the combined effects of micro fin structure and nanofluids on the heat transfer enhancement, it could be found that a comprehensive performance factor that simultaneously considers the improvements of heat transfer and pressure drop was calculated in the most studies. However, not all the results of performance factor could indicate that combination of two enhancement techniques have positive effects to enhance heat transfer performance. This phenomenon illustrates again the necessity and urgency of research in this field.

In this study, one type of multiport minichannel flat tube (MMFT) was used as the test section. MMFTs are widely applied in various fields as a heat exchanger unit due to the efficient heat transfer performance. Moreover, one type of continuous fin structure along axial direction (two-dimensional fin) in micro/minichannel also was used in this study. This type of fin structure can be fabricated by heat extrusion with MMFT at one time, which is a much simpler and more low-cost technique compared with those of the staggered fin array (three-dimensional fin) which are investigated in 
1

\subsection{MMFT}

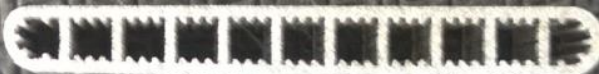

(a)

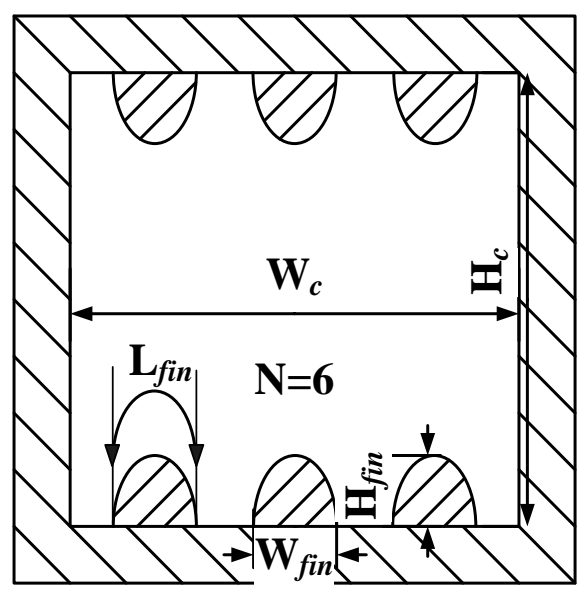

(b)

\section{MMFT and Nanofluid}

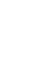

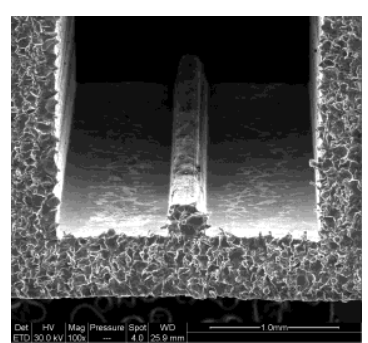

Sample 2

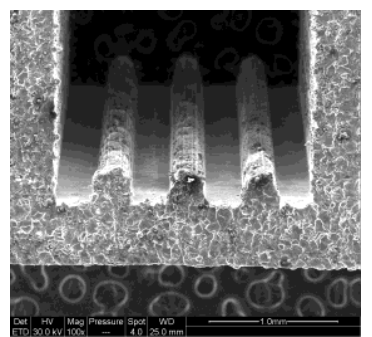

Sample 4

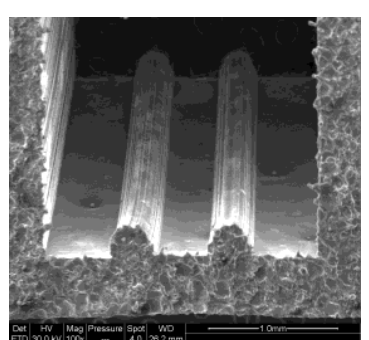

Sample 3

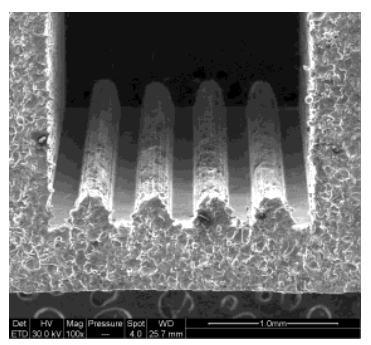

Sample 5
9

most literatures. An experimental investigation of single-phase convection of $\mathrm{TiO}_{2}$ water nanofluid in MMFTs with different fin numbers was presented in this paper,<smiles>CCCCCCCC</smiles>

In this study, five aluminum MMFTs with different fin numbers were fabricated and used as test sections, which are defined as sample 1, sample 2, sample 3, sample 4 and sample 5 respectively. Taking sample 4 as an example, Fig. 1a shows the cross-section 
1 of MMFT. Five MMFTs are all composed of 11 parallel and independent square

2 minichannels. Moreover, except for the fin number, five MMFT have same other

3 parameters, including both dimension and shape of each square minichannel and fin

4 structure. Fig. 1b illustrates the schematic drawing of an independent square

5 minichannels with micro fin structure. The height and weight of channel $\mathrm{H}_{c}$ and $\mathrm{W}_{c}$

6 both are $2 \mathrm{~mm}$, while height of fin $\mathrm{H}_{f}$ and bottom width $\mathrm{W}_{f}$ of fin are $0.24 \mathrm{~mm}$ and 0.28

7 mm respectively. Fig.1c presents a scanning electron microscopy (SEM) photograph of

8 fins for Sample 2-5. As shown in figures, fins are distributed symmetrically at the upper

9 and lower internal surfaces of each minichannel and fabricated continuously along axial direction, and thereby can be considered as two-dimensional structure. Fin numbers of Sample 1-5 are 0, 2, 4, 6 and 8 respectively. Therefore, sample 1 is a smooth tube without fin structure, and the experimental results using this tube as test section and water as working fluid can not only verify the integrity of the experimental facility but also provide baseline information to compare the improvement of heat transfer performance using different enhancement techniques.

\subsection{Nanofluid}

$\mathrm{TiO}_{2}$-water nanofluids with $0.005 \%, 0.01 \%$ and $0.1 \%$ volume concentrations were prepared by two-step method in this study. The production method of nanofluids is characterized by the following steps: firstly, adding $\mathrm{TiO}_{2}$ nanoparticles with particle diameter $\mathrm{d}_{p}=10 \mathrm{~nm}$ into base fluid, water. Cetyl trimethyl ammonium bromide (CTAB), a dispersant with mass that is 0.2 times higher than that of the nanoparticles, was then dispersed in the water. Finally, the solid-liquid mixture was oscillated in an ultrasonic 
1

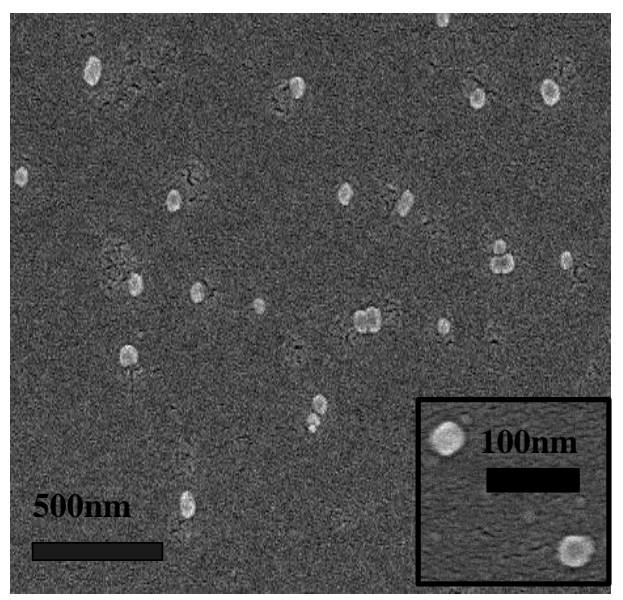

(a) required longer oscillation time. different volume concentrations.

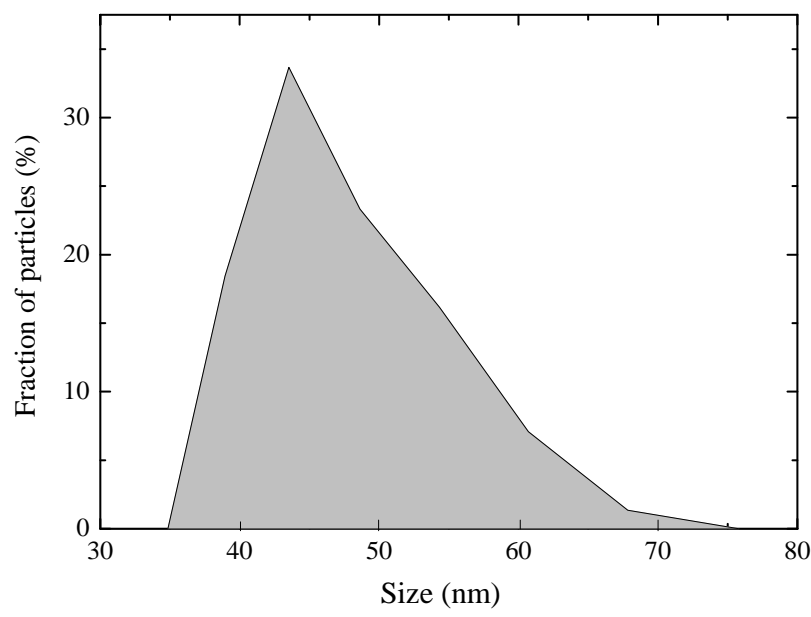

(b)

washer for $1 \mathrm{~h}$ and then allowed stand for another hour. The final step was repeated but oscillation was instead conducted for 3-5 h. Mixtures with higher volume concentration

In order to investigate particle distribution and effective particle size in the suspensions, scanning electron microscopy (SEM) and dynamic light scattering (DLS) were adopted respectively for nanofluids with different volume concentrations. Taking $0.01 \%$ nanofluid as an example, Fig. 2a and Fig. $2 \mathrm{~b}$ show SEM image and particle size distribution of $0.01 \% \mathrm{TiO}_{2}$-water nanofluid respectively. From Fig. 2a, it can be found that nanoparticles distribute uniformly in the suspensions and particle size is about 50 $\mathrm{nm}$, which is consistent with the result obtained by DLS measurement and much bigger than $10 \mathrm{~nm}$ specified by the supplier. Moreover, it should be noted that the test results reveal no significant difference in effective particle size among nanofluids with

\footnotetext{
Fig. 2 (a) SEM image and (b) DLS measurement of effective particle size $\left(0.01 \% \mathrm{TiO}_{2}\right.$-water nanofluid)
} 

used in the data reduction. The effective density and specific heat of the nanofluid are

3 calculated by

4

5

$$
\begin{gathered}
\rho_{n f}(T)=(1-\varphi) \rho_{b f}(T)+\varphi \rho_{p}(T) \\
c_{p, n f}=\frac{\varphi \cdot\left(\rho c_{p}\right)_{p}(T)+(1-\varphi)\left(\rho c_{p}\right)_{b f}(T)}{\rho_{n f}(T)}
\end{gathered}
$$

The effective thermal conductivity of nanofluids were measured by using a transient

hot wire method under different temperatures and compared with the theoretical values calculated with the model of Yu and Choi [20] and Kleinstreuer and Feng correlation [21]. In this study, the measurement data of thermal conductivity are reasonably correlated with the theoretical values from Kleinstreuer and Feng correlation [21]. Taking $0.1 \% \mathrm{TiO}_{2}$-water nanofluid as an example, Fig. 3 shows the comparisons of the measurement values and theoretical values under different temperatures. It can be found that the relative errors between these two values are about $1 \%$, which indicates that model of Kleinstreuer and Feng correlation can [21] be used to predict the effective thermal conductivity of $\mathrm{TiO}_{2}$-water nanofluids in this study.

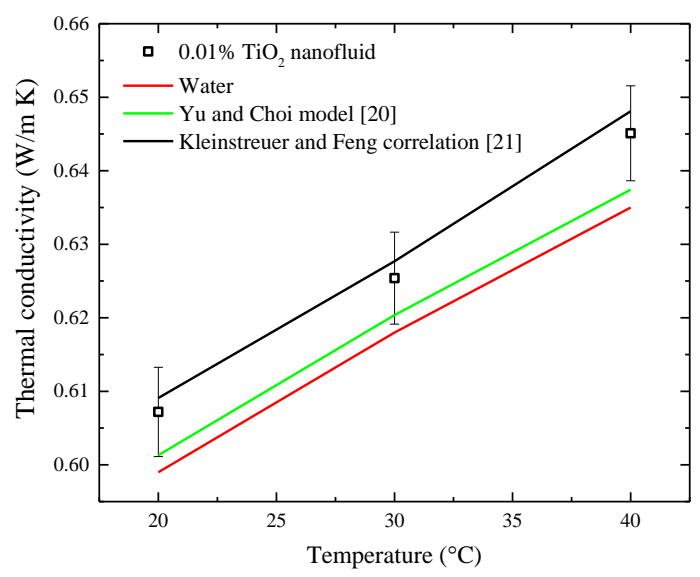


2 The effective viscosity of the nanofluids was measured using a rotating viscometer 3 and the relative viscosity of the nanofluids at $20{ }^{\circ} \mathrm{C}$ is presented in Fig. 4, along with 4 the well-known Batchelor correlation [22]

$$
\mu_{n f}=\mu_{b f}\left(1+2.5 \varphi+6.25 \varphi^{2}\right)
$$

6 From the figure, it can be found that the viscosity ratio of nanofluid to water increases

7 with the increase of volume concentration and is higher than that obtained by Batchelor 8 correlation [22].

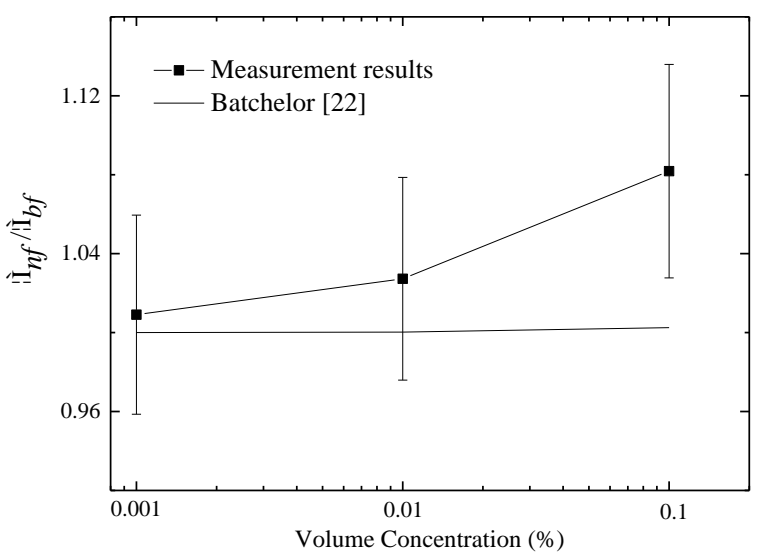

Fig. 4 Effective viscosity of the nanofluid at various volume concentrations (error bar $\pm 5 \%$ )

\section{Experimental apparatus}

Fig. 5 shows the schematic of test section. As well known, a manifold which induce a uniform flow distribution in each channel and keep the fluid at a stable state is of crucial importance in the experimental test of parallel flow multilayer channels. In this study, the inlet and outlet of MMFT are connected with a manifold respectively by braze welding. Moreover, thermal resistors and pressure transducer are installed in the 

7 thermal insulation.

manifolds to measure temperature and pressure difference of the test section inlet and outlet. Two heating plates are covered the upper and lower wall surfaces of MMFT to provide constant heat flux. Meanwhile, between the MMFT and heating plate, five flat thermal resistances are fixed with equidistance on the upper and lower surface of MMFT respectively to measure the axial wall surface temperature distribution. Finally, test section is tightly wrapped by $50 \mathrm{~mm}$-thick thermal insulation material to achieve

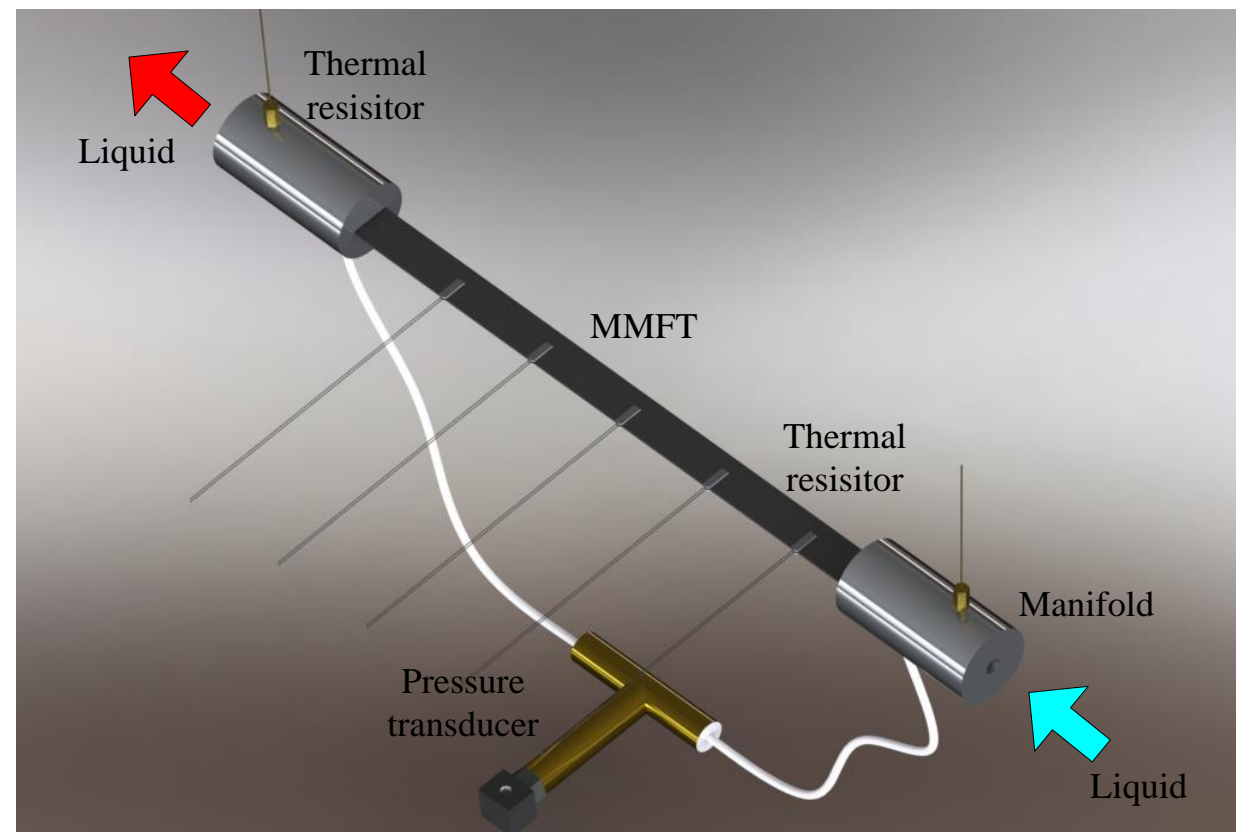

Fig. 5 Schematic of test section

The schematic of test system is presented in Fig. 6. The working fluid is driven from liquid storage tank by pump and then flow through filter, Coriolis mass flow meter and test section. In order to recover initial temperature, the working fluid heat in the test section enters into the double-pipe heat exchanger and cooled with water coolant provided by water chilling unit. Finally, working fluid flow back to liquid storage tank, 
1 finishing the main loop.

$$
D_{h}=\frac{4 A}{c}=\frac{4\left(H_{c} W_{c}-A_{f i n}\right)}{2 H_{c}+2 W_{c}+N\left(L_{f i n}-W_{f i n}\right)} \quad \text { and } \quad \alpha=\frac{W_{c}}{H_{c}}
$$

$$
\Delta p=\Delta p_{f r i}+\Delta p_{m}
$$

The total pressure differential in the test section is expressed as

Frictional pressure loss is calculated using Eq. (7), and singular pressure loss $\left(\Delta \mathrm{P}_{m}\right)$ is 
1 calculated using the method mentioned in the Ref. [23].

$$
f=\Delta p_{f r i} \frac{D_{h}}{L} \cdot \frac{\rho_{f} \cdot\left(\mathrm{H}_{\mathrm{c}} \mathrm{W}_{\mathrm{c}}-\mathrm{A}_{\mathrm{fin}}\right)^{2}}{\dot{m}^{2}}
$$

3 The heat gained by the fluid that is heated throughout the test section is expressed as

4

$$
Q=\dot{m} \cdot c_{p} \cdot\left(T_{f, \text { out }}-T_{f, \text { in }}\right)
$$

5 The heat flux can be calculated from the heat gain by the fluid as

6

$$
q=\frac{Q}{L_{c} \cdot P e}
$$

7 According to the energy balance, the fluid temperature at longitudinal $\mathrm{x}$ position is

8 calculated as

9

$$
\mathrm{T}_{f}(x)=\mathrm{T}_{f, i n}+\frac{Q}{\dot{m} \cdot c_{p, f}(x) \cdot L} \cdot x
$$

The local heat transfer coefficient is given by

$$
h(x)=\frac{q}{\mathrm{~T}_{w}(x)-\mathrm{T}_{f}(x)}
$$

Based on the energy balance, heat loss rate is defined as

$$
\varepsilon=\frac{V I-\dot{m} \cdot c_{p} \cdot\left(T_{f, \text { out }}-T_{f, \text { in }}\right)}{V I}
$$

The local Nusselt number is defined as

$$
N u(x)=\frac{h(x) \cdot D_{h}}{k_{f}(x)}
$$




$$
\operatorname{Re}(x)=\frac{\dot{m} \cdot D_{h}}{A \cdot \mu_{f}(x)}
$$

2 Accordingly, the averaged Nusselt number and Reynolds number are given by

3

$$
\overline{N u}=\sum_{n=1}^{10} N u_{n} \text { and } \overline{\operatorname{Re}}=\sum_{n=1}^{10} \operatorname{Re}_{n}
$$

\section{$4 \quad 4.2$ Uncertainties analysis}

5 In this study, the uncertainties in temperature and mass flow rate measurements are

$6 \pm 0.1^{\circ} \mathrm{C}$ and $\pm 0.2 \%$, respectively. The error associated with the pressure difference 7 transducer is $\pm 0.25 \%$. The uncertainties of the parameters calculated by using

8 directly measured values, such as $f, N u$, and $R e$, are generally denoted as $\delta \mathrm{z}$ and 9 calculated as

$$
\mathrm{z}=\mathrm{f}\left(y_{1}, y_{2} \cdots \cdots y_{n}\right)
$$

$$
\delta z=\left[\left(\frac{\partial z}{\partial y_{1}} \delta y_{1}\right)^{2}+\left(\frac{\partial z}{\partial y_{2}} \delta y_{2}\right)^{2}+\cdots \cdots+\left(\frac{\partial z}{\partial y_{n}} \delta y_{n}\right)^{2}\right]^{\frac{1}{2}}
$$

12 where $\delta \mathrm{y}_{1}, \delta \mathrm{y}_{2}, \ldots . . \delta \mathrm{y}_{\mathrm{n}}$ are the uncertainties of directly measured values.

13 The test ranges and uncertainties of some relevant parameters are summarized in 14 Table 1.

Table 1 Operating conditions

\begin{tabular}{lll|lll}
\hline & value & uncertainty & & value & uncertainty \\
\hline $\mathrm{G}(\mathrm{Kg} / \mathrm{h})$ & $10-405$ & $0.2 \%$ & $\mathrm{D} h(\mathrm{~mm})$ & $2.02-2.05$ & $2.0-2.5 \%$ \\
$\mathrm{~A}_{\text {fin }}\left(\mathrm{mm}^{2}\right)$ & $0.08-0.31$ & $3.5-7 \%$ & $\mathrm{Re}$ & $129-5650$ & $2.2-11.2 \%$ \\
& & & & & \\
\hline
\end{tabular}




\begin{tabular}{lll|lll}
\hline $\mathrm{T}_{w}(\mathrm{~K})$ & $294-315$ & $0.1 \mathrm{~K}$ & $f$ & $0.025-0.6$ & $3.2-15.2 \%$ \\
$\mathrm{~T}_{f}(\mathrm{~K})$ & $292-302$ & $0.1 \mathrm{~K}$ & $\mathrm{Nu}$ & $4.57-52$ & $3.6-15.9 \%$ \\
$\mathrm{Q}(\mathrm{W})$ & $185-208$ & $3.1-8.0 \%$ & $\mathrm{PEC}$ & $0.93-2$ & $4.6-17.2 \%$ \\
\hline
\end{tabular}

1

2 5. Results and discussion

3 For the experimental investigations, the pressure drop and heat transfer

4 characteristics of Sample 1 were firstly studied, which aims to verify the integrity of

5 the experimental facility and provide baseline information to compare the experimental

6 results using different enhancement techniques. Next, research just using one

7 enhancement technique were performed. Specifically, the pressure drop and heat

8 transfer characteristics of water in sample 2-5 and nanofluids in sample 1 were studied.

9 Finally, the experimental results using two combined enhancement techniques were

10 obtained and then compared with those of previous experiments.

\subsection{Experiments with sample 1}

2 The friction factor is plotted as functions of Reynolds number in Fig. 5, together with the Shah and London [24] correlation for a fully developed laminar flow in rectangular channels,

$$
f . \operatorname{Re}=96\left(1-1.3553 \cdot \alpha+1.9467 \cdot \alpha^{2}-1.7012 \cdot \alpha^{3}+0.9564 \cdot \alpha^{4}-0.2537 \cdot \alpha^{5}\right)
$$

The well-known Blasius [25] correlation for fully developed turbulent flows, 

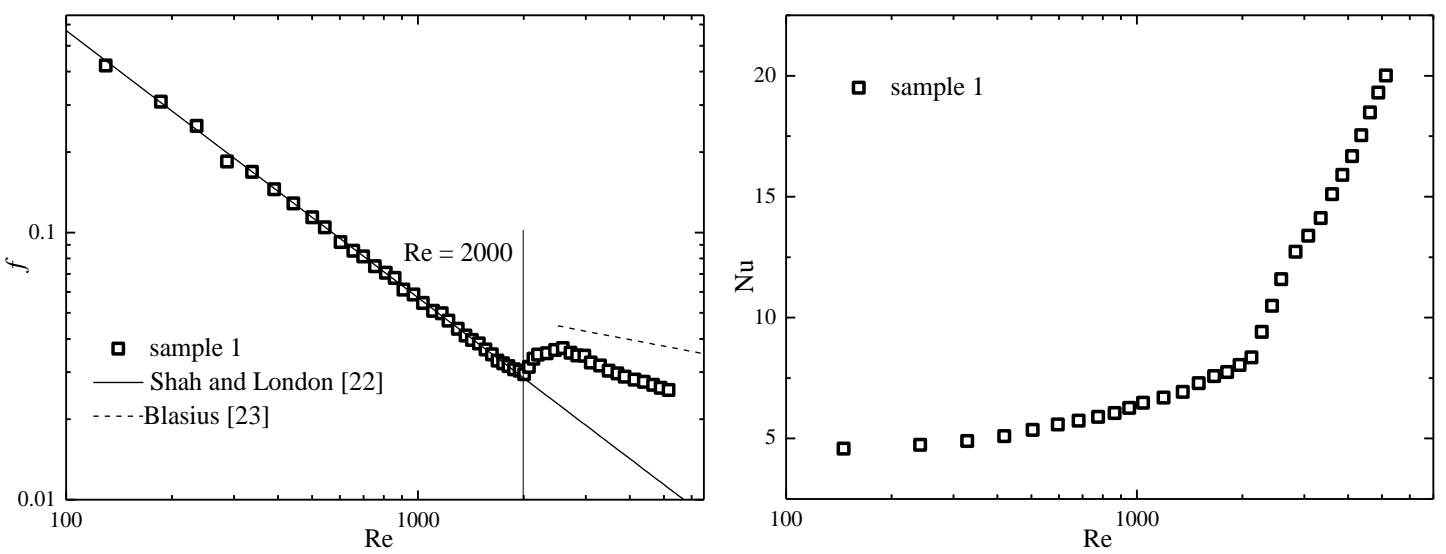

Fig. 7(a) Friction factor and (b) Nusselt number versus Reynolds number for sample 1

\subsection{Experiments with one enhancement technique}

In this section, flow and heat transfer characteristics of sample 2-5 using water as working fluid were investigated. Fig. 8(a) shows friction factors of sample 1-5. It is 
1 observed that friction factor of all samples with the fin structure is higher than that of

2 smooth tube, sample 1 and the friction factor increases with the increase of fin number.

3 From Fig. 8(a), it is further observed that for sample 2-5 with the fin structure, an earlier

4 laminar-turbulent transition occurs at $\operatorname{Re}=1500-1900$ compared with the result of

5 sample 1. This behavior could be attributed to the more significant disturbance in the

6 flow caused by fin structure. The earliest laminar-turbulent transition occurs about at

$7 \quad \operatorname{Re}=1500$ for sample 5. Fig. 8(b) shows averaged Nusselt numbers of sample 1-5.

8 Nusselt number of the samples with the fin structure is higher than that of sample 1.

9 The Nusselt number also increases with the increase of fin number and Nusselt number can increase by up to $135 \%$ for sample 5 .

11
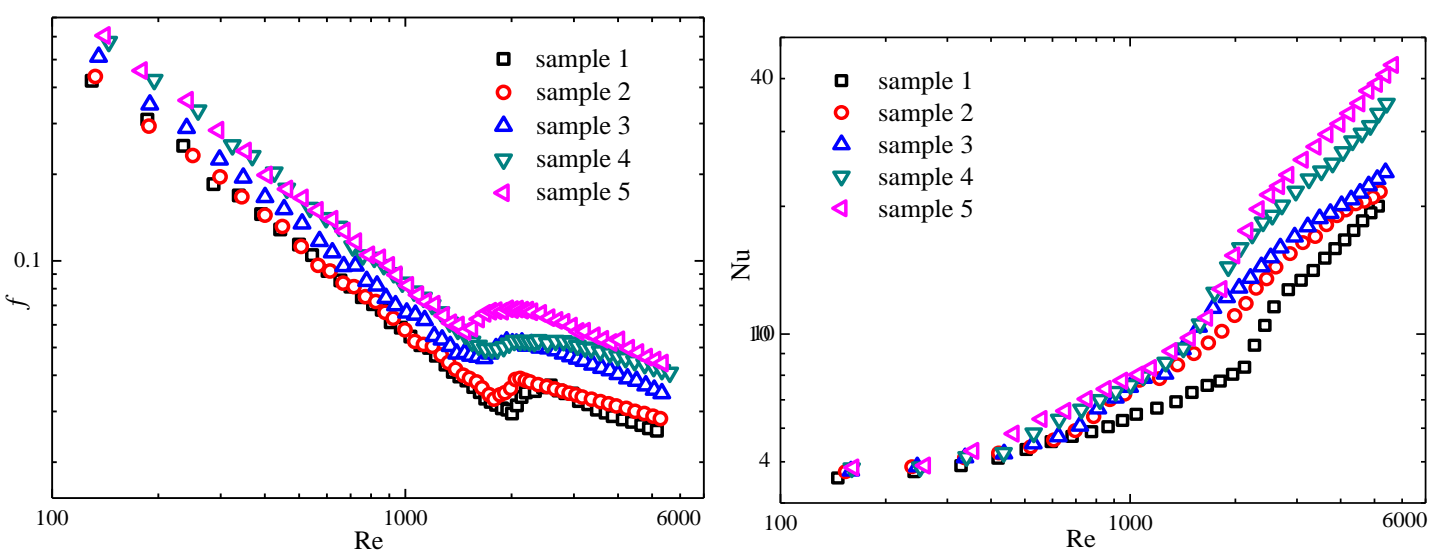

Fig. 8(a) Friction factor and (b) Nusselt number versus Reynolds number for sample 1-5

Flow and heat transfer characteristics of sample 1 using $\mathrm{TiO}_{2}$-water nanofluids as working fluid were also investigated next. In Fig. 9(a), friction factors of nanofluids at various volume concentrations are plotted against the Reynolds number. The friction factors of nanofluids are all higher than those of water and increase with the increase of volume concentrations. The average Nusselt numbers of nanofluids are plotted 
1 against the Reynolds number at various volume concentrations in Fig. 9(b). As shown

2 in the figure, Nusselt numbers of nanofluids also are all higher than those of water,

3 especially in the turbulent region. Furthermore, at $\varphi \leqslant 0.01 \%$, Nusselt numbers

4 increase with the increase in volume concentration; at $\varphi \geqslant 0.01 \%$, Nusselt numbers

5 decrease with the increase in volume concentration, which indicates an optimal volume

6 concentration of $0.01 \%$ for heat transfer performance. This phenomenon is consistent

7 with the experimental results in Ref. [26-27]. As explained in Ref. [27], this

8 phenomenon is attributed to the combined effect of the increases in thermal

9 conductivity and viscosity. With the increase in volume concentration, thermal

10 conductivity and viscosity both increase. The former can strengthen heat transfer,

11 whereas the latter can weaken heat transfer due to the increase in the thickness of the

12 thermal boundary layer. At $\varphi \leqslant 0.01 \%$, the positive effects of the thermal

13 conductivity enhancement in the present work overcome the negative effect of viscosity.

14 The opposite cases are true at $\varphi \geqslant 0.01 \%$. On the other hand, the energy exchanges

15 between particles and particles, particles and water, and particles and wall resulting

16 from the chaotic movement of nanoparticles enhance heat transfer. With the increase in

17 volume concentration, more particles exist per unit volume. In the experiments

18 conducted in this work, such kind of energy exchanges seem to weaken as the particle

19 number increases to a certain value because large particle numbers may restrict the

20 chaotic movement of nanoparticles. Nevertheless, the mechanism of the microscopical

21 movement of nanoparticles for enhancing heat transfer need be studied further. 

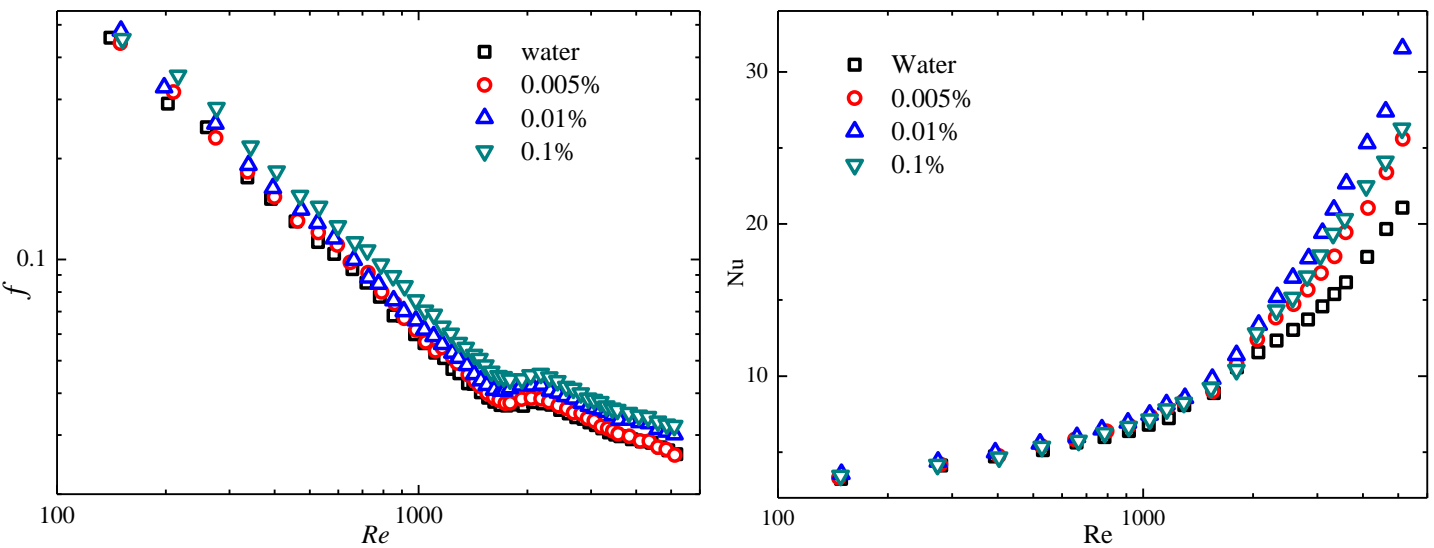

Fig. 9(a) Friction factor and (b) Nusselt number versus Reynolds number of nanofluids in sample 1

From above experimental results, it can be found that regardless of which enhancement technique used, heat transfer can be enhanced but tend to increased pressure drop. Thus, as a comprehensive assessment of nanofluid performance in terms of heat transfer enhancement, a performance evaluation criterion (PEC) based on the same pumping power consumption is defined as [28]

$$
P E C=\frac{N u_{n f, \text { samples } 2-5} / N u_{\text {water }, \text { sample } 1}}{\left(f_{n f, \text { sample } 2-5} / f_{\text {water }, \text { sample } 1}\right)^{1 / 3}}
$$

Fig. 10 presents the PEC values of samples 2-5 and nanofluids with different volume concentration. As shown in the figure, PEC values of sample 2-5 are all higher than 1, which demonstrates that using micro fin does enhance heat transfer performance. Among sample 2-5, sample 5 has the highest PEC values and maximum value of PEC is 1.83 for sample 5 at about $\operatorname{Re}=2300$. Moreover, for using nanofluids as working fluids, except for $0.1 \%$ nanofluids and $\operatorname{Re}<2000$, the nanofluids could enhance heat transfer performance without huge penalty of increased pumping power under other conditions. $0.01 \%$ nanofluid has the best PEC in all nanofluids and the maximum value 
1 is 1.43 occurring at $\operatorname{Re}=5100$.

7 in sample 1. The friction factors of nanofluids in sample 2-5 are plotted as functions of

8 Reynolds number in Fig. 11 respectively. Compared with water in sample 1, nanofluids

9 in samples with fin structures have the higher friction factors and show the earlier

10 laminar-turbulent transition which is attributed to the effects of enhanced disturbance

11

\subsection{Experiments with two combined enhancement techniques}

In this section, the enhanced heat transfer performance were studied by using nanofluids in MMFTs with fin structures and comparing with the initial results of water caused by micro fin structures.

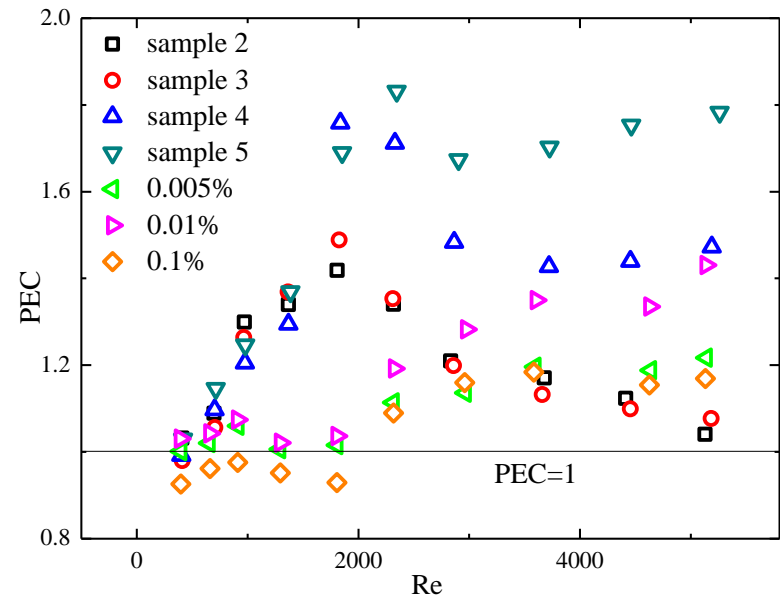

Fig. 10 PEC values versus Reynolds number for samples 2-5 and nanofluids with different $\varphi$ 
1

2

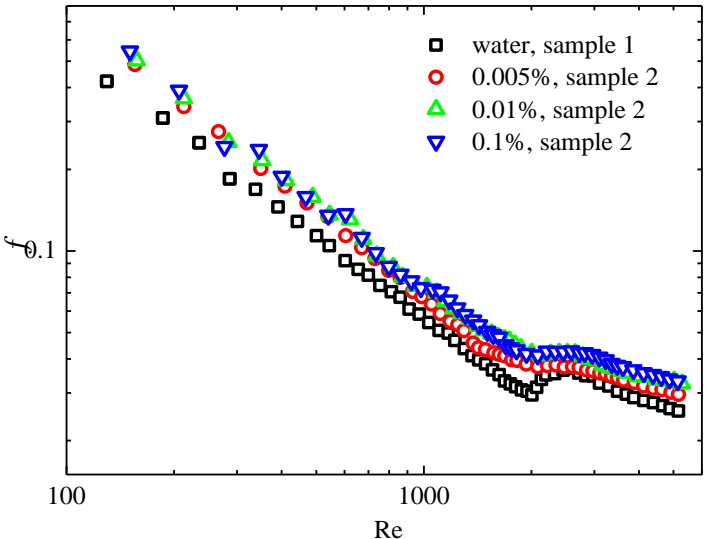

(a)

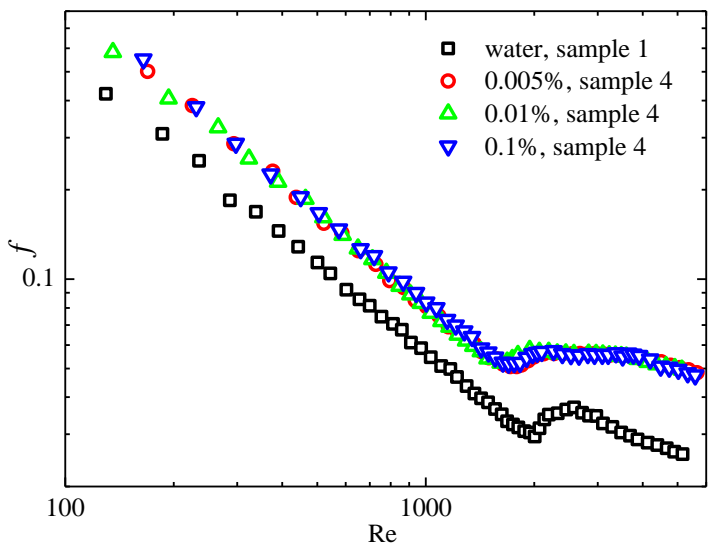

(c)

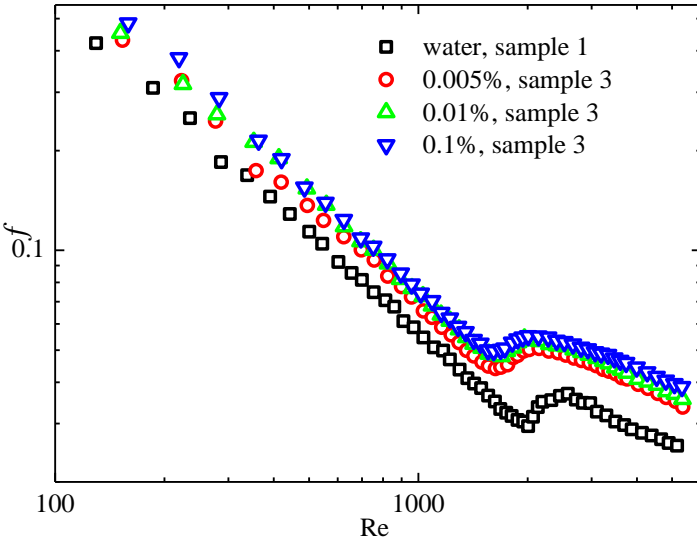

(b)

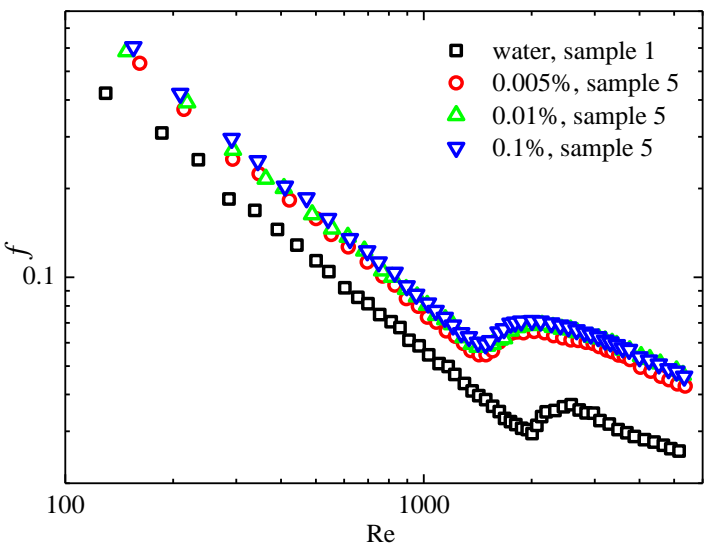

(d)

5 Fig. 11 Comparison of friction factors between water in sample 1 and $\mathrm{TiO}_{2}$-water nanofluids in (a) samples 2, (b) sample 3, (c) sample 4 and (d) sample 5

7

8 Table 2 Average increase of $f$ using enhancement techniques with respect to the water in sample 1

\begin{tabular}{llllll}
\hline & Sample 1 & Sample 2 & Sample 3 & Sample 4 & Sample 5 \\
& - & $3.5 \%$ & $21.2 \%$ & $36.9 \%$ & $43.9 \%$ \\
Water & & & & & \\
& & & & & \\
$0.005 \%$ nanofluid & $2.9 \%$ & $16.4 \%$ & $31.7 \%$ & $58.2 \%$ & $61.9 \%$ \\
$0.01 \%$ nanofluid & $10.9 \%$ & $26.1 \%$ & $41.4 \%$ & $61.4 \%$ & $71.9 \%$ \\
& & & & & \\
$0.1 \%$ nanofluid & $21.7 \%$ & $30.0 \%$ & $47.6 \%$ & $65.7 \%$ & $77.5 \%$ \\
\hline
\end{tabular}


To illustrate the effect of enhancement techniques on flow characteristic, Table 2

2 summarizes the increase in the friction factor of nanofluids in sample 2-5 as with

3 respect to the water in sample 1. From the comparison, it can be found that the friction

4 factor increases with the increases of the volume concentrations of nanofluids as well

5 as the fin number. A maximum $77.5 \%$ average increase of friction factor occurs for $0.1 \%$

$6 \quad$ nanofluid in sample 5.

7

8

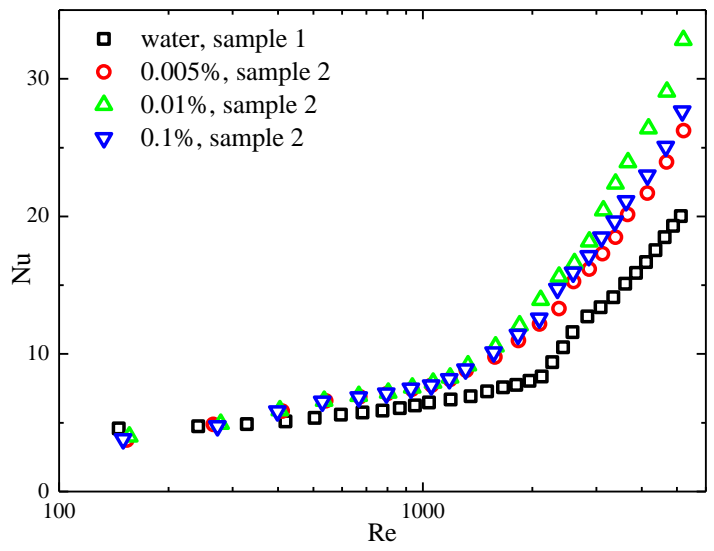

(a)

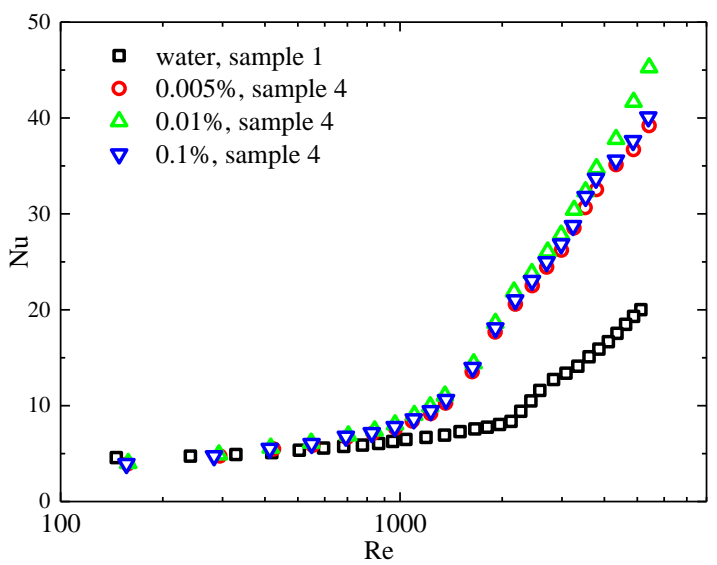

(c)

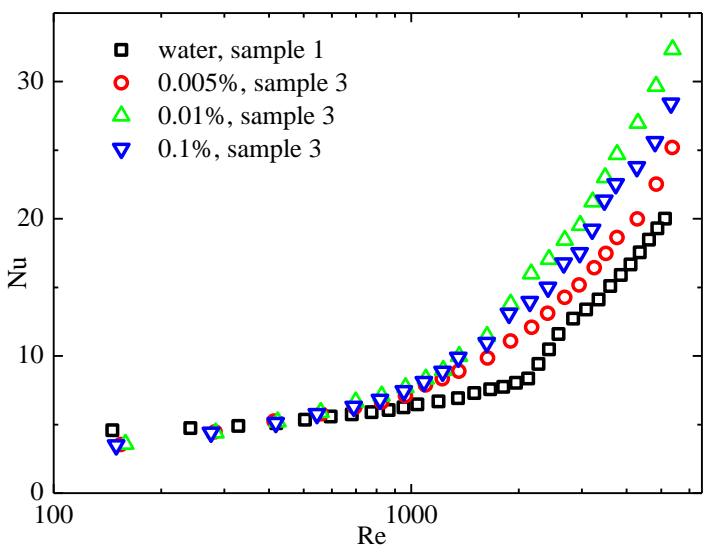

(b)

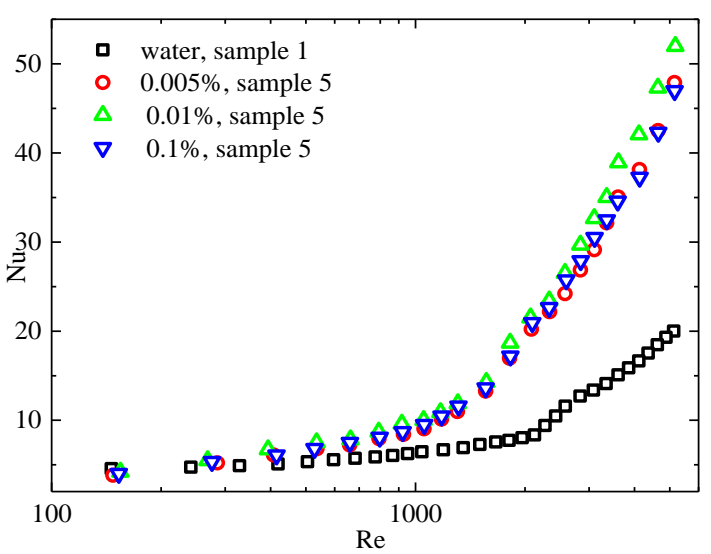

(d)

11 Fig. 12 Comparison of Nusselt numbers between water in sample 1 and $\mathrm{TiO}_{2}$-water nanofluids in (a) samples 2, (b) sample 3, (c) sample 4 and (d) sample 5

Fig. 12 shows Nusselt numbers of nanofluids in sample 2-5 compared with those of 
1 water in sample 1 . As shown in the figure, all Nusselt numbers obtained by using two

2 combined enhancement techniques are much higher than those of water in sample 1,

3 especially in the turbulent region. Similarly, the increases of Nusselt number in laminar

4 and turbulent regions for nanofluids in sample 2-5 as with respect to the water in sample

$5 \quad 1$ are listed in Table 3 respectively. The quantified analysis of heat transfer enhancement

6 shown in Table 3 indicate that combination of two enhancement techniques could

7 further increase the Nusselt number compared with just using one enhancement

8 technique. From Table 3, it can be further found that for each working condition, the

9 increase of $\mathrm{Nu}$ in turbulent region is much higher than that in laminar region. As concluded in Ref. [29], two main mechanisms caused by micro fin structure can be used to explain the heat transfer enhancement. Specifically, based on continuous fin structure along axial direction, the increase in heat transfer area due to exist of micro fin is dominant in the laminar region, while more disturbances caused by fin structure has more significant effect on heat transfer enhancement in the turbulent region. In this case, micro fin structure causes more disturbances in turbulent flow, which contributes to more intense irregular movement of nanoparticles. Due to the stronger chaotic movement of nanoparticles, the energy transport among the wall, fluid, and particles become stronger and thereby improve heat transfer performance. Therefore, the heat transfer enhancement in turbulent region is more remarkable. can be found that heat transfer performances of nanofluids mainly depend on two factors, nanofluid concentration and fin structure (fin number), which indicates that 
1 these two factors both have significant effects on energy transport of nanofluids. From

2 the further comparison in Table 3, it can be found that the average increase of Nusselt

3 number increases up to $21 \%$ for just changing the concentrations, while the average

4 increase of Nusselt number increases up to $91 \%$ for just changing the fin numbers.

5 Therefore, it seems that fin structure has more significant effects on heat transfer

6 performance of nanofluids than nanofluids concentration in this study.

7 Table 3 Average increase of Nusselt numbers using enhancement techniques with respect to the 8 water in sample 1

\begin{tabular}{|c|c|c|c|c|c|c|c|c|}
\hline & \multicolumn{2}{|l|}{ water } & \multicolumn{2}{|c|}{$0.005 \%$ nanofluid } & \multicolumn{2}{|c|}{$0.01 \%$ nanofluid } & \multicolumn{2}{|c|}{$0.1 \%$ nanofluid } \\
\hline & Lam. & Tur. & Lam. & Tur. & Lam. & Tur. & Lam. & Tur. \\
\hline Sample 1 & - & - & $3.4 \%$ & $15.7 \%$ & $8.3 \%$ & $33.5 \%$ & $4.0 \%$ & $21.2 \%$ \\
\hline Sample 2 & $12.4 \%$ & $22.2 \%$ & $13.8 \%$ & $31.6 \%$ & $22.7 \%$ & $55.1 \%$ & $19.3 \%$ & $39.2 \%$ \\
\hline Sample 3 & $18.8 \%$ & $32.7 \%$ & $18.9 \%$ & $34.6 \%$ & $23.2 \%$ & $59.4 \%$ & $19.8 \%$ & $42.1 \%$ \\
\hline Sample 4 & $24.8 \%$ & $77.3 \%$ & $32.0 \%$ & $107.2 \%$ & $38.9 \%$ & $123.7 \%$ & $34.7 \%$ & $112.0 \%$ \\
\hline Sample 5 & $30.9 \%$ & $112.7 \%$ & $40.6 \%$ & $125.0 \%$ & $53.6 \% \%$ & $146.1 \%$ & $44.4 \%$ & $128.1 \%$ \\
\hline
\end{tabular}

9

The optimal volume concentration is also $0.01 \%$ for nanofluids in each sample, which is consistent with the conclusion obtained in the smooth tube-sample 1 and Nusselt number increases with increase of fin number. The Nusselt number of $0.01 \%$ nanofluid in sample 5 are highest while Nusselt number in laminar and turbulent region can averagely increase by $53.6 \%$ and $146.1 \%$ respectively. Nusselt number increases by up to $158 \%$ at about $\operatorname{Re}=3600$. 
1 From above experimental results, it can be concluded that although using nanofluids

2 as work fluid in the MMFT with fin structures could increase Nusselt number, it also

3 accompany with the higher pressure drop. Therefore, in order to discuss whether using

4 nanofluids in MMFT with fin structure (sample 2-5) can further improve heat transfer

5 performance compared with using water in sample 2-5, a new parameter $\mathrm{PEC}_{n f}$ is

$6 \quad$ introduced and defined as

7

$$
P E C_{n f}=\frac{N u_{n f, \text { samples2-5 }} / N u_{n f, \text { sample } 1}}{\left(f_{n f, \text { sample 2-5 }} / f_{n f, \text { sample } 1}\right)^{1 / 3}}
$$

8 From the Eq. (20), it could be found that the baseline data is the test results of nanofluids

9 in sample 1 when the $\mathrm{PEC}_{n f}$ is calculated. Fig. 13 shows the $\mathrm{PEC}_{n f}$ values of sample 2-

5. As shown in the figure, $\mathrm{PEC}_{n f}$ is irregular with the varying of Reynolds number in term of each working condition. Moreover, not all the $\mathrm{PEC}_{n f}$ values are higher than 1 , which illustrates that adding nanofluids into MMFT with fin structure to further improve heat transfer performance is not universally applicable. Specifically, a better heat transfer performance can be obtained by using $0.01 \%$ nanofluids in sample $3-5$.

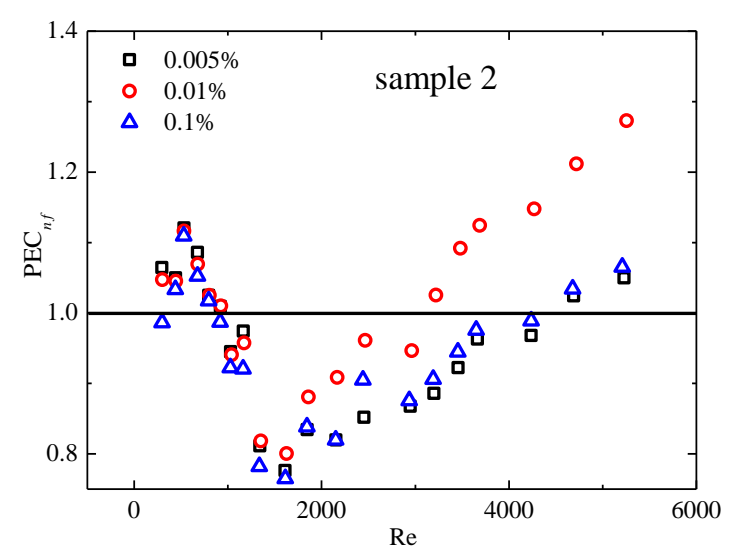

(a)

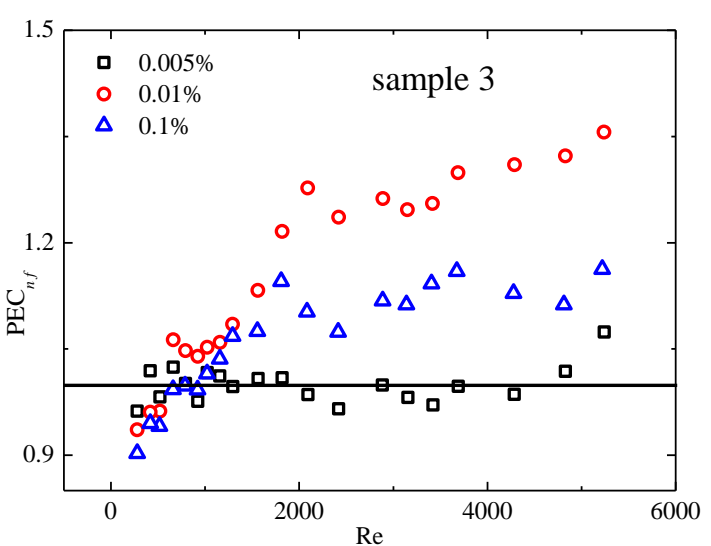

(b) 


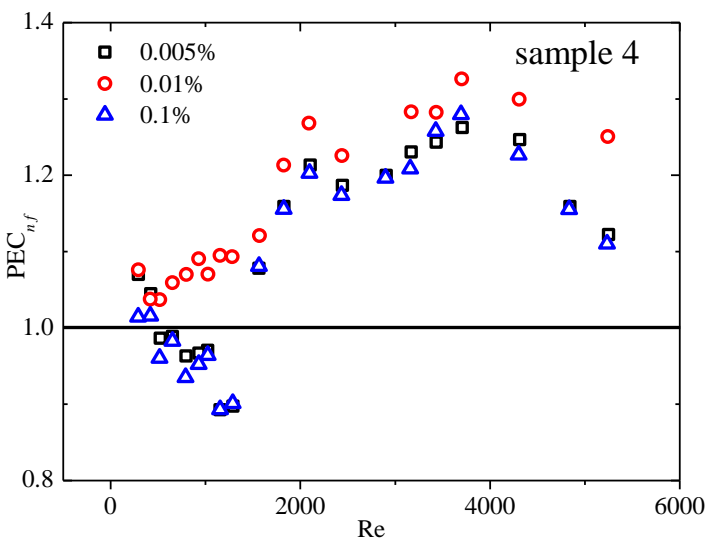

(c)

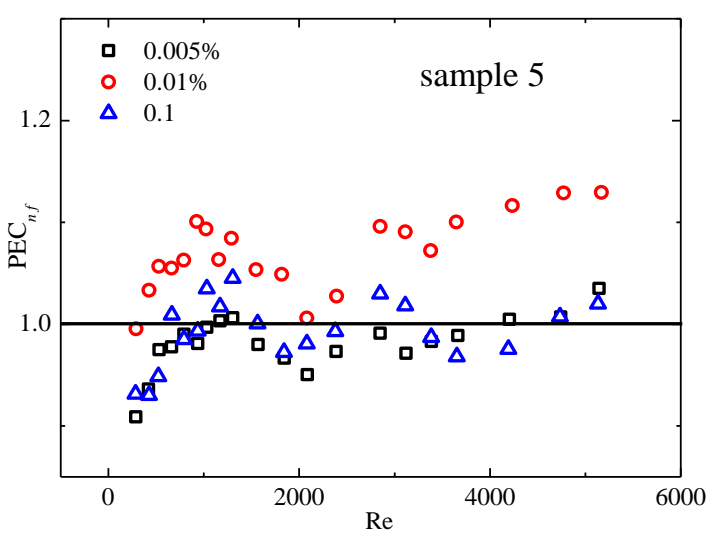

(d)

3 Fig. 13 PEC $_{n f}$ values versus Reynolds number in (a) sample 2, (b) sample 3, (c) sample 4 and (d) sample 5

Based on above conclusion, PEC values under several potential optimal working condition in this study are presented in Fig. 14, including PECs of $0.01 \%$ nanofluid in sample 1 and sample 3-5 and water in sample 5. Generally, 0.01\% nanofluid in sample 5 has the highest PEC values. The maximum PEC values of $0.01 \%$ nanofluid in sample 5 are 2.0 as $\operatorname{Re}=5150$. Moreover, using water in sample 5 also can achieve the good performance, which is attributed that PECs of water in sample 5 are higher than those of other working conditions except for $0.01 \%$ nanofluid in sample 5 and are even higher than those of $0.01 \%$ nanofluid in sample 5 as Reynolds number ranges about from 1700 to 2500 . From the Fig. 14, it can be further found that micro fin structure has the better heat transfer performance than nanofluids in term of just using one enhancement technique. 


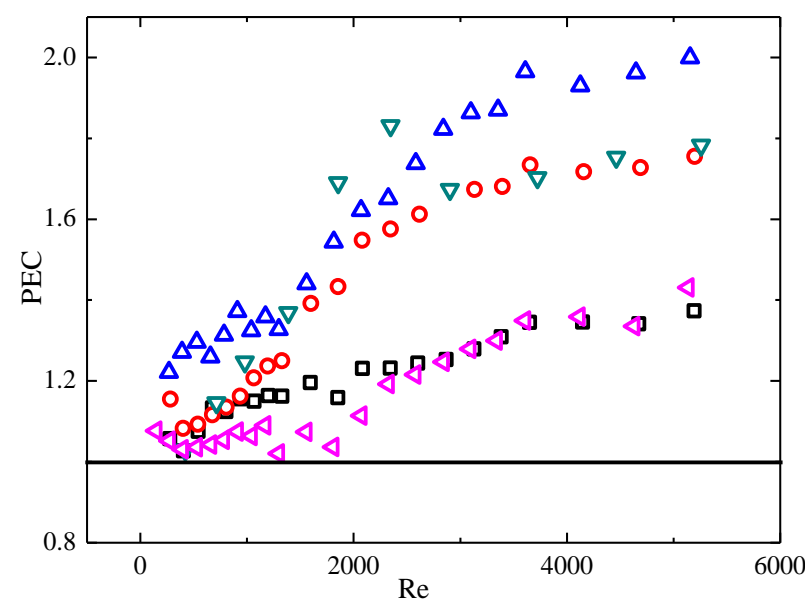

$\quad 0.01 \% \mathrm{TiO}_{2}$-water sample3 $\quad$ o $0.01 \% \mathrm{TiO}_{2}$-water sample $4 \quad \Delta \quad 0.01 \% \mathrm{TiO}_{2}$-water sample 5

$\nabla \quad$ water, sample $5 \triangleleft 0.01 \% \mathrm{TiO}_{2}$-water, sample 1

Fig. 14 Comparison of PEC under several conditions

Finally, the PECs obtained under two optimal working conditions $(0.01 \%$ nanofluid and water in sample 5 respectively) in this study are compared with those of other research, which are shown in Fig. 15. From the comparison, it can be found that two sets of PEC values in this study increase with the increase of Reynolds number in the turbulent region, which is attributed that improvement of heat transfer is higher than the increase of pressure drop. This behavior is much different with the results of other research shown in Fig .15, which presents the decrease of PEC with the increase of Reynolds number in the larger Reynolds numbers (turbulent region). In Ref. [30-34], different kinds of inserts including twist, porous medium, coiled wire and twisted-ring used as turbulators were installed in the tube to enhance heat transfer performance. As well-known, the heat transfer enhancement caused by turbulator is more significant in laminar region. However, as mentioned above, heat transfer enhancements in this study that come from either energy transfer between nanoparticles and fluids or disturbances caused by fin structure both are stronger in the turbulent region. Therefore, different 
1 enhancement mechanisms cause different growth characteristics of heat transfer

2 performance, and thereby the trend of PEC in present study is quite different from those

3 in the research using inserts as turbulator [30-34]. Comparing with the results in Ref.

4 [35-36] where only using nanofluid technique was used, it can be found that

5 combination of two enhancement techniques could obtain better heat transfer

6 performance. Unfortunately, due to the restriction of pressure drop, the test data in

7 larger Reynolds numbers could not be measured in this study. The corresponding

8 research need to be further studied and then compared with the results in similar

9 research. Generally, using enhancement technique in this study shows a good PEC

10 value and applicability to improve the heat transfer performance.

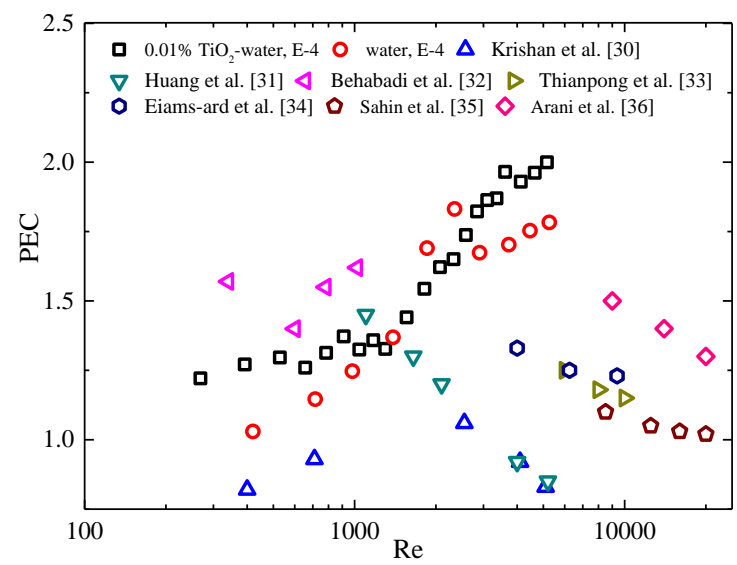

Fig. 15 Comparison of PEC values in this study with those of other research

\section{Conclusion}

The enhanced heat transfer performances by using two enhancement techniques (micro fin structure and nanofluid) both respectively and conjunctively were studied. Through testing the friction factor, Nusselt number as well as PEC, the key findings can 
be concluded as follows.

(1) The Nusselt number and friction factor in samples with micro fin strictures increase with the increase of fin numbers and also are both higher than those in smooth sample. Moreover, using $\mathrm{TiO}_{2}$-water nanofluids as working fluids also can improve the heat transfer but tend to increase pressure drop.

(2) Either micro fin structure or nanofluid is a suitable enhancement technique to improve the heat transfer performance in MMFT. Furthermore, from the comparison of these two enhancement techniques, using samples with micro fin structure has the higher PEC values than using nanofluid as working fluid in smooth sample.

(3) Compared with water in the sample with fin structure, only using nanofluid with volume concentration of $0.01 \%$ instead of water can further enhance the heat transfer generally. The optimal working condition is running $0.01 \%$ nanofluid in sample 5 . Under this working condition, Nusselt number increases by up to $158 \%$ at about $\mathrm{Re}=$ 3600 and the maximum PEC value is 2.0 as $\mathrm{Re}=5150$.

(4) An optimal heat transfer scheme was proposed based on experimental results in this study. Generally, alone employ of micro fin technique is recommended due to its excellent heat transfer performance as well as the economic consideration. The combination of two enhancement techniques suggests to be employed in the turbulent region to face the demand of higher heat flux removal rate. 


\section{References}

[1] D. B. Tuckerman, R. F. Pease, High Performance Heat Sinking for VLSI, IEEE Electron Device Letter, 2(1981), 126-129.

[2] S. G. Kandlikar, S. Colin, Y. Peles, S. Garimella, R. F. Pease, J. J. Brandner, D. B. Tuckerman, Heat Transfer in Microchannels-2012 Status and Research Needs, Transactions of the ASME, Journal of heat transfer, 135(2013) 091001.

[3] Z. Wun, B. Sundén, On further enhancement of single-phase and flow boiling heat transfer in micro/minichannels, Renewable and Sustainable Energy Reviews, $40(2014) 11-27$.

[4] Ali Koşar, Yoav Peles, Thermal-Hydraulic Performance of MEMS-based Pin Fin Heat Sink, Journal of Heat Transfer, 128 (2006) 121-131.

[5] Weilin Qu, Abel Siu-Ho, Liquid Single-Phase Flow in an Array of Micro-PinFins_-Part I: Heat Transfer Characteristics, Journal of Heat Transfer, 130 (2008) 122402.

[6] Yoav Peles, Ali Koşar, Chandan Mishra, Chih-Jung Kuo, Brandon Schneider, Forced convective heat transfer across a pin fin micro heat sink, International Journal of Heat and Mass Transfer, 48 (2005) 3615-3627.

[7] Minghou Liu, Dong Liu, Sheng Xu, Yiliang Chen, Experimental study on liquid flow and heat transfer in micro square pin fin heat sink, International Journal of Heat and Mass Transfer, 54 (2011) 5602-5611. 
1 [8] Y. J. Lee, P. S. Lee, S. K. Chou, Enhanced Thermal Transport in Microchannel

$2 \quad$ Using Oblique Fins, Journal of Heat Transfer, 134 (2012) 101901.

3 [9] Jie Li, Clement Kleinstreuer, Thermal performance of nanofluid flow in

4 microchannels, International Journal of Heat and Fluid Flow 29 (2008) 1221-1232.

5 [10] Jung-Yeul Jung, Hoo-Suk Oh, Ho-Young Kwak, Forced convective heat transfer 6 of nanofluids in microchannels, International Journal of Heat and Mass Transfer 52 $7 \quad$ (2009) 466-472.

[11] M.R. Sohel, R. Saidur, Mohd Faizul Mohd Sabri, M. Kamalisarvestani, M.M. Elias,

9 Ali Ijam, Investigating the heat transfer performance and thermophysical properties of nanofluids in a circular micro-channel, International Communications in Heat and Mass Transfer 42 (2013) 75-81.

[12] C.J. Ho, W.C. Chen, An experimental study on thermal performance of $\mathrm{Al}_{2} \mathrm{O}_{3} /$ water nanofluid in a minichannel heat sink, Applied Thermal Engineering 50 (2013) 516-522.

[13] Clement Kleinstreuer, Zelin $\mathrm{Xu}$, Mathematical Modeling and Computer 
1 Banerjee, Experimental study of forced convective heat transfer of nanofluids in a

2 microchannel, International Communications in Heat and Mass Transfer 39 (2012)

$3 \quad 1325-1330$.

4 [16] M. Khoshvaght-Aliabadi, F. Hormozi, A. Zamzamian, Experimental analysis of

5 thermal-hydraulic performance of copper-water nanofluid flow in different plate-fin

$6 \quad$ channels, Experimental Thermal and Fluid Science 52 (2014) 248-258.

7 [17] Majid Roshani, Seyed Ziaeddin Miry, Pedram Hanafizadeh, Mehdi Ashjaee,

$8 \quad$ Hydrodynamics and heat transfer characteristics of a miniature plate pin-fin heat sink

9 utilizing $\mathrm{Al}_{2} \mathrm{O}_{3}$-water and $\mathrm{TiO}_{2}$-water nanofluids.

[18] S. Eiamsa-ard, K. Wongcharee, Single-phase heat transfer of $\mathrm{CuO} /$ water nanofluids in micro-fin tube equipped with dual twisted-tapes, International Communications in Heat and Mass Transfer 39 (2012) 1453-1459.

[19] Weerapun Duangthongsuk, Somchai Wongwises, A comparison of the heat transfer performance and pressure drop of nanofluid-cooled heat sinks with different miniature pin fin configurations, Experimental Thermal and Fluid Science 69 (2015) $111-118$.

[20] W. Yu and S.U.S. Choi, The role of interfacial layers in the enhanced thermal conductivity of nanofluids: A renovated Maxwell model, Journal of Nanoparticle Research 5 (2003) 167-171.

[21] Zelin $\mathrm{Xu}$, Clement Kleinstreuer, Concentration photovoltaic-thermal energy cogeneration system using nanofluids for cooling and heating, Energy Conversion and 
2 [22] G. K. Batchelor, The effect of Brownian motion on the bulk stress in a suspension

3 of spherical particles, Journal of Fluid Mechanics 83 (1977) 97-117.

4 [23] Bruno Agostini, André Bontemps, Bernard Thonon, Effects of Geometrical and

5 Thermophysical Parameters on Heat Transfer Measurements in Small-Diameter $6 \quad$ Channels, Heat Transfer Engineering, 27 (2006) 14-24.

7 [24] Shah, R., and London, A., Laminar Flow Forced Convection in Ducts, Academic $8 \quad$ Press, London, 1978.

9 [25] Incropera, F., and DeWitt, D., Fundamentals of Heat and Mass Transfer, 4th ed., $10 \quad$ John Wiley and Sons, New York, 1994.

[26] Ji Zhang, Yanhua Diao, Yaohua Zhao, Yanni Zhang, Experimental study of TiO2water nanofluid flow and heat transfer characteristics in a multiport minichannel flat tube, International Journal of Heat and Mass Transfer 79(2014) 628-638.

[27] Ji Zhang, Yanhua Diao, Yaohua Zhao, Yanni Zhang, Thermal-Hydraulic Performance of SiC-Water and $\mathrm{Al}_{2} \mathrm{O}_{3}$-Water Nanofluids in the Minichannel, Journal of Heat Transfer, 138 (2016) 021705.

[28] R.L. Webb, Performance evaluation criteria for use of enhanced heat transfer surfaces in heat exchanger design, International Journal of Heat and Mass Transfer 24 (1981) 715-726.

[29] Ji Zhang, Yaohua Zhao, Yanhua Diao, Yanni Zhang, An experimental study on 
1 fluid flow and heat transfer in a multiport minichannel flat tube with micro-fin

2 structures, International Journal of Heat and Mass Transfer 84 (2015) 511-520.

3 [30] S. R. Krishna, G. Pathipaka, P. Sivashanmugam, Heat transfer and pressure drop

$4 \quad$ studies in a circular tube fitted with straight full twist, Experimental Thermal and $5 \quad$ Fluid Science, 33 (2009) 431-438.

6 [31] Z. F. Huang, A. Nakayama, K. Yang, C. Yang, W. Liu, Enhancing heat transfer in

7 the core flow by using porous medium insert in a tube, International Journal of Heat $8 \quad$ and Mass Transfer, 53 (2010) 1164-1174.

9 [32] M. A. Akhavan-Behabadi, R. Kumar, M. R. Salimpour, R. Azimi, Pressure drop and heat transfer augmentation due to coiled wire inserts during laminar flow of oil inside a horizontal tube, International Journal of Thermal Sciences, 49 (2010) 373379.

[33] C. Thianpong, K. Yongsiri, K. Nanan, S. Eiamsa-ard, Thermal performance evaluation of heat exchangers fitted with twisted-ring turbulators, International Communications in Heat and Mass Transfer, 39 (2012) 861-868.

[34] S. Eiamsa-ard, N. Koolnapadol, P. Promvonge, Heat Transfer Behavior in a Square Duct with Tandem Wire Coil Element Insert, Chinese Journal of Chemical Engineering, 20 (2012) 863-869.

[35] B. Sahin, G. G. Gültekin, E. Manay, S. Karagoz, Experimental investigation of heat transfer and pressure drop characteristics of $\mathrm{Al}_{2} \mathrm{O}_{3}$-water nanofluid, Experimental Thermal and Fluid Science, 50 ( 2013) 21-28. 
1 [36] A.A. Abbasian Arani, J. Amani, Experimental investigation of diameter effect on

2 heat transfer performance and pressure drop of $\mathrm{TiO}_{2}$-water nanofluid, Experimental

$3 \quad$ Thermal and Fluid Science, 44 (2013) 520-533.

4

5

6

7

8

9

10

11

12

13

14

15

16

17

18

19

20

21 